\title{
Where is the game? Wild meat products authentication in South Africa: a case study
}

\author{
Maria Eugenia D'Amato ${ }^{1 *}$, Evguenia Alechine ${ }^{2}$, Kevin Wesley Cloete' ${ }^{1}$ Sean Davison ${ }^{1}$ and Daniel Corach²
}

\begin{abstract}
Background: Wild animals' meat is extensively consumed in South Africa, being obtained either from ranching, farming or hunting. To test the authenticity of the commercial labels of meat products in the local market, we obtained DNA sequence information from 146 samples (14 beef and 132 game labels) for barcoding cytochrome c oxidase subunit I and partial cytochrome $b$ and mitochondrial fragments. The reliability of species assignments were evaluated using BLAST searches in GenBank, maximum likelihood phylogenetic analysis and the characterbased method implemented in BLOG. The Kimura-2-parameter intra- and interspecific variation was evaluated for all matched species.

Results: The combined application of similarity, phylogenetic and character-based methods proved successful in species identification. Game meat samples showed $76.5 \%$ substitution, no beef samples were substituted. The substitutions showed a variety of domestic species (cattle, horse, pig, lamb), common game species in the market (kudu, gemsbok, ostrich, impala, springbok), uncommon species in the market (giraffe, waterbuck, bushbuck, duiker, mountain zebra) and extra-continental species (kangaroo). The mountain zebra Equus zebra is an International Union for Conservation of Nature (IUCN) red listed species. We also detected Damaliscus pygargus, which is composed of two subspecies with one listed by IUCN as 'near threatened'; however, these mitochondrial fragments were insufficient to distinguish between the subspecies. The genetic distance between African ungulate species often overlaps with within-species distance in cases of recent speciation events, and strong phylogeographic structure determines withinspecies distances that are similar to the commonly accepted distances between species.

Conclusions: The reliability of commercial labeling of game meat in South Africa is very poor. The extensive substitution of wild game has important implications for conservation and commerce, and for the consumers making decisions on the basis of health, religious beliefs or personal choices.

Distance would be a poor indicator for identification of African ungulates species. The efficiency of the character-based method is reliant upon availability of large reference data. The current higher availability of cytochrome $b$ data would make this the marker of choice for African ungulates. The encountered problems of incomplete or erroneous information in databases are discussed.
\end{abstract}

Keywords: Biltong, Conservation, Cytb, DNA barcoding, Food forensics, Meat, Species identification

\section{Background}

The consumption of game meat is popular in southern Africa, especially in dry form. The consumption of wild ungulates - loosely called 'game' - and ostrich is viewed as a healthy alternative to beef, because of their low content of fat and cholesterol [1] and for the natural origin of game products, devoid of antibiotics, anabolic

\footnotetext{
* Correspondence: medamato@uwc.ac.za

'Biotechnology Department, Forensic DNA Lab, University of the Western

Cape, Modderdam Road, Bellville 7535, South Africa

Full list of author information is available at the end of the article
}

steroids, hormones and other additives, in an increasingly health-aware market. Game meat is consumed mostly dry in southern Africa. Traditional preparations have been locally consumed since colony times: 'biltong' consists of strips of meat seasoned with vinegar and spices and dried with hot air, whereas 'droë wors' are simply hot-air dried sausages for long-term storage. The market trend in favor of game meat is reflected in the increase in ranching from 600,000 head of game in 1964 to 18.6 million in 2007 , with a result that $80 \%$ of game animals are being kept on private land [2]. Currently,

\section{Biomed Central}


20.5 million ha of marginal agricultural land are owned by over 10,000 commercial wildlife ranching farms containing 2.5 million heads of game. This commercial activity is predominantly driven by the dry meat demand $[2,3]$. Hunting is also an important source of wild meat for the specific purpose of biltong production [4]. A conservative estimation of the magnitude of this activity indicates that over 1 million animals are hunted yearly (Peet van der Merwe, personal communication), with a contribution to gross domestic product that exceeds ZAR 6 billion (USD 750 million) [5]. The preferential targets are springbok (Antidorcas marsupialis), impala (Aepyceros melampus), blesbok (Damaliscus pygargus phillipsi) and kudu (Tragelaphus strepsiceros). Intensive farming is reserved for ostrich (Struthio camelus) production.

Ranched and hunted game in South Africa and Namibia is distributed in the form of dressed carcasses to supermarkets and butcheries by wholesalers or hunters. According to the South African Meat Safety Act 40 of 2002 [6], meat from wild animals sold for human consumption must be accompanied by a permit, and the meat must be processed by an accredited abattoir and approved upon regulated inspection. However, these regulations do not apply to biltong hunters [7], who most frequently butcher the hunt themselves [8].

Biltong is manufactured both industrially and in smallscale family businesses, resulting in a mixed market of branded and unbranded products. In South Africa, the game industry is a free market enterprise devoid of central marketing structure [3]. The labeling of game meat and biltong relies largely - or solely - on wholesalers and manufacturers. The delivery of head- and skin-off dressed carcasses and the general lack of regulations increase the chances of species mislabeling and product substitution or fraud. It is surprising that the list of most frequently hunted game shows over 20 species [8] whereas only seven can be found in the local market: springbok, kudu, gemsbok (Oryx gazella), impala, eland (Tragelaphus oryx), wildebeest (Connochaetes species) and ostrich.

Of no less concern is the possibility of intentional delivery of endangered species in the meat market. In South Africa, the Convention on International Trade in Endangered Species of Wild Fauna and Flora (CITES) [9] listed endangered ungulate species are the bontebok Damaliscus pygargus pygargus (synonym $D$. dorcas dorcas, D. p. dorcas) (CITES Appendix II), the cape mountain zebra Equus zebra zebra (CITES Appendix I), the southern white rhinoceros Ceratotherium simum simum (CITES Appendix I), the black rhinoceros Diceros bicornis (CITES Appendix I) and the African elephant Loxodonta africana (CITES Appendix II). The International Union for Conservation of Nature (IUCN) Red
List of Threatened Species 2012 [10] catalogued these species as 'vulnerable' (E. zebra, L. africana), 'critically endangered' (Diceros bicornis), 'near threatened' (Ceratotherium simum simum) and 'of least concern' ( $D$. p. pygargus).

The identity of meat and other wildlife products is of common interest for both food science and protection of biodiversity. The most frequently applied techniques involve the analysis of markers such as mitochondrial DNA (mtDNA) fragments of cytochrome b (cytb), Dloop, cytochrome c oxidase subunit I (COI), 12S rRNA and $16 \mathrm{~S}$ rRNA coding regions, and STRs with a variety of typing techniques reviewed in [11-14].

The early availability of universal primers for cytb $[15,16]$ fuelled studies of molecular evolution and made a large number of sequences available. The most studied cytb fragment is 358 bp long, and its relatively high level of intraspecific and interspecific variation made it attractive for phylogenetic and phylographic studies. The widespread application of COI in conservation and evolution is more recent, resulting from the establishment of the Barcode of Life Data Systems (BOLD) database $[17,18]$. This situation determines a higher availability of information for cytb. The cytb:COI ratio for Cetartiodactyla (even-toed ungulates) and Perissodactyla (odd-toed ungulates) taxa represented in GenBank (accessed in July 2012) is 2.5 and 4.5 respectively.

This COI underrepresentation bias will likely be reversed with the growth of the BOLD database. BOLD banks DNA sequence information of a 648 bp fragment of COI, coined 'barcode', along with other valuable biological data such as voucher number and institution of origin. The high quality control of DNA sequence information to identify a species is a clear advantage over GenBank, in which the deposition of false sequences has been reported [19-21].

The suitability of cytb versus COI in animal forensics has long been debated. A study by Tobe et al. [22] provided a guideline for the reliability of species identification using cytb and COI. Compared with COI, cytb demonstrated a higher phylogenetic signal and a higher power to correctly identify species, therefore making cytb a more attractive marker for forensic applications. Tobe et al. used whole mitochondrial genome sequences of Canis, Homo and Bos and 236 cytb and COI mammal sequences, and estimated the within-species variation to be lower than a Kimura-2-parameter (K2P) distance $(\times 100)$ of 1.5 for both mtDNA fragments, whereas the differences between species had a K2P $(\times 100)$ value higher than 2.5. Using the COI barcoding region, Hebert et al. [17] suggested a $3 \%$ threshold of sequence divergence for within-species variation. Subsequently, it was suggested a 10-fold rule for within-species versus between-species K2P genetic distance [23]. 
Most DNA sequence information available for African ungulates comes from phylogenetic and phylogeographic studies using the cytb or D-loop region. The application of cytb and COI to conservation and food studies is very scarce in Africa: COI barcoding sequences have been made available for central and western African mammalian species [24-27]. To date, the sole study of species authenticity in the South African commercial market was conducted on fish species using $16 \mathrm{~S}$ rDNA and $84 \%$ substitution was evidenced [28].

Here, we present a case study of species identification in wild meat food products in South Africa. The identifications were performed by means of comparative DNA sequence information using the mtDNA gene fragments cytb and COI. We applied three different methods: a similarity method implemented in the $\mathrm{Na}$ tional Center for Biotechnology Information GenBank database [29]; a phylogenetic method to identify monophyletic clusters; and a character-based logic mining method that infers diagnostic characters from reference sequences for further classification [30]. The significance of matches in GenBank was further evaluated by means of phylogenetic reconstruction and by evaluation of the extent of known variation within and between species. By following this approach we intend to overcome the possibility of identification uncertainty arising from incomplete taxa availability; incomplete or lack of withinspecies genetic information in databases; and evolutionary events such as incomplete lineage sorting, secondary contact and consequent hybridization, cryptic speciation, and other populations processes. This is the first study of this nature for game food commercial products conducted in South Africa.

\section{Methods}

We applied basic laboratory practices according to Budowle et al. [31] and followed the recommendations of the International Society for Forensic Genetics for non-human DNA typing [32].

\section{Samples}

A total of 146 samples were collected from wholesalers, supermarkets and outlets. Labels indicated the collected products were beef (Bos taurus $\mathrm{N}=14$ ), generic 'game' $(\mathrm{N}=6)$, springbok $(\mathrm{N}=33)$, gemsbok $(\mathrm{N}=14)$, impala $(\mathrm{N}=4)$, blesbok $(\mathrm{N}=2)$, kudu $(\mathrm{N}=38)$, eland $(\mathrm{N}=8)$, blue wildebeest (Connochaetes taurinus) $(\mathrm{N}=1)$, ostrich ( $\mathrm{N}=23$ ), zebra (either cape mountain or Burchell's zebra E. quagga burchellii $\left.{ }^{\mathrm{a}}\right)(\mathrm{N}=1)$ and warthog (Phacochoerus africanus) $(\mathrm{N}=2)$. All beef samples consisted of biltong, whereas game samples were obtained in the form of biltong $(\mathrm{N}=94)$, droë wors (dry sausages) $(\mathrm{N}=30)$, fresh and minced meat $(\mathrm{N}=10)$, carpaccio $(\mathrm{N}=6)$, fresh sausages $(\mathrm{N}=2)$ and smoked meat $(\mathrm{N}=4)$.

Voucher specimens with known classification and relevant collection information (photo and global positioning system co-ordinate) were collected. Reference samples for the following species was obtained either from the National Zoological Gardens of South Africa, South African National Parks and the Quagga Project Association or with the assistance of various South African conservation agencies: cape mountain zebra, $(\mathrm{N}=6)$, Burchell's zebra $(\mathrm{N}=2)$, bontebok $(\mathrm{N}=$ $5)$, blesbok $(\mathrm{N}=4)$, black wildebeest (Connochaetes gnou, $\mathrm{N}=2)$, blue wildebeest $(\mathrm{N}=3)$, springbok $(\mathrm{N}=3)$, nyala (Tragelaphus angasii, $\mathrm{N}=1)$, eland $(\mathrm{N}=1)$, gemsbok $(\mathrm{N}=1)$. The origin and species of these samples are known as all zoos participate in animal record-keeping databases and the International Species Information System and confirm speciation according to IUCN guidelines.

Single DNA extractions and analyses were performed for biltong, carpaccio, fresh meat and smoked meat whereas, for fresh and dry sausages, DNA sequence information was obtained from at least two small samples from different dissected fractions of approximately $\leq 1$ $\mathrm{mm}^{2}$ (fat and meat). DNA was extracted following a salting-out method [33] modified by increasing the proteinase $\mathrm{K}$ concentration to $0.1 \mathrm{mg} / \mathrm{ml}$ in a lysis volume of $500 \mu \mathrm{L}$. DNA was resuspended in $50 \mu \mathrm{L}$ bidistilled water and quantified using a Nanodrop ND-2000 spectrophotometer (Thermo Fisher Scientific, Wilmington, USA).

\section{PCR and sequencing}

DNA polymorphisms were analyzed for cytb and COI. We used the universal vertebrate cytb primers L14816 5'-CCATCCAACATCTCAGCATGATGAAA-3' and H1 5173 5'-CCCCTCGAATGATATTTGTCCTCA-3' [34], positioned between sites 14583 and 14941 in the $B$. taurus mtDNA reference sequence V00654 [35]. COI barcoding region primers [36] were redesigned to overcome difficulties found during amplification. The primers L5701 5'-CTGAYTATTYTCAACYAACCAYAA AGA-3' and H6418 5'-ATAKACTTCRGGGTGTCCRA AGAATCA-3' were designated according to their position and amplicon size using the $B$. taurus mtDNA reference sequence V00654 [35]. Macropus-specific COI primers were designed for samples with mixtures of two or more species after Macropus species were identified from the same samples with cytb sequence data: MACRCOI-F 5'-TAGGAACTGCCTTAAGTCTGCTC-3' and MACR-COI-R 5'-TGAAAGGAGAAGGAGGACTGCT G-3'. Amplifications were performed in a Verity Thermal Cycler (Applied Biosystems, Singapore) in a final volume of $25 \mu \mathrm{L}$ containing $25 \mathrm{ng}$ DNA, $2 \mathrm{mM}$ deoxyribonucleotide triphosphates, $0.4 \mathrm{mM}$ primers, $1 \mathrm{U}$ 
Super Therm Taq polymerase (JMR Holdings, Kent, UK). PCR cycling conditions were $94^{\circ} \mathrm{C}$ for $3 \mathrm{~min}$ followed by 35 cycles of $94^{\circ} \mathrm{C}$ for $30 \mathrm{~s}, 45^{\circ} \mathrm{C}$ (cytb) or $50^{\circ} \mathrm{C}$ (COI) for $30 \mathrm{~s}$, and $72^{\circ} \mathrm{C}$ for $45 \mathrm{~s}$ with a final extension time of $72^{\circ} \mathrm{C}$ for $10 \mathrm{~min}$. PCR products were checked on $2 \%$ agarose gels in $1 \times$ tris-borate-EDTA buffer, and sequencing reactions in both directions were either outsourced to Macrogen (Seoul, South Korea), or performed in our facilities in $10 \mu$ reaction final volume with BigDye Terminator v 3.1 (Life Technologies, Foster City, CA, USA). Sequencing products were resolved in an ABI 3130XL (Applied Biosystems, Japan) at the Central Analytical Facility of Stellenbosch University and in our facilities.

\section{Species identification, validation and data analyses}

Species DNA identification was initially assessed by BLAST [29] searches in GenBank [37] using the maximum similarity values from pairwise alignments. All available entries for the matched species and related species from the same genera and tribe were used for phylogenetic analysis and for evaluating the range of genetic variation within and between species. Entries from environmental samples (for example, food, mosquito bloodmeal) were excluded from our analyses. GenBank accession numbers of sequences used for all analyses are provided in Table S1 in Additional file 1.

DNA sequence alignments were performed with Clustal W implemented in BioEdit Sequence Alignment Editor 7.0.9.0 [38]. Mean K2P [39] genetic distance was calculated for unique sequences within species, and net between-groups mean K2P distance was calculated between species. Standard errors were calculated with 1,000 bootstrap replicates. Sister species were identified either from whole mitochondrial genomes in the phylogenetic analysis of Hassanin et al. [40], or from our phylogenetic analysis.

Maximum likelihood (ML) phylogenetic trees were constructed using the K2P substitution model with uniform rates among sites, treating missing data using the partial-deletion option, and applying the Nearest Neighbor Interchange heuristic method. Branch support was evaluated with 1,000 bootstraps as implemented in MEGA v. 5.0 [41].

The character-based method implemented in BLOG v. 2.0 [42] was applied to the identification of 'classes' (species) in each alignment. This method extracts diagnostic characters from reference sequences for the classes (species) used for 'training' and infers diagnostic formulae for each class using a learning algorithm. These formulae are applied to classify the test sequences. The padding parameter was set to 1 for the uneven length of some reference sequences; all other parameters were applied at default values. BLOG was shown to perform better than similarity and neighbor-joining, parsimony or Bayesian phylogenetic methods [42].

Identifications were scored as 'correct' when cytb and COI DNA sequence information obtained from multiple dissections indicated the same species as the commercial label, and 'false' when either both or one DNA fragment was non-coincidental with the species indicated by the product label.

\section{Results and discussion}

\section{Market substitution statistics}

A total of 151 COI [GenBank:JX567005-JX567156] and 152 cytb [GenBank:JX567157-JX157309] DNA sequences were obtained from the 146 collected food samples, and 29 COI [GenBank:JX436976-JX436996; JX566994-JX 567001] and seven cytb [GenBank:JX436997-JX437000; JX567002-JX567004] DNA sequences from known reference samples. Detailed information of the food samples, GenBank accession numbers, and identification results are provided in Table S2 in Additional file 2.

The cytb and COI analysis of 146 commercial red meat samples indicated that 101 were false (69.18\%). Excluding the samples collected as 'beef', which were all correctly labeled, the strict substitution of wild meat then becomes $76.5 \%$ (Table 1). Of all substitutions, 49 samples indicated domestic or alien species: thirty-five beef, one horse (E. caballus), six kangaroo (Macropus giganteus, $M$. rufus, and $M$. robustus and an unidentified Macropus species), one pork (Sus scrofa) and seven lamb (Ovis aries). All other substitutions indicated other African wild species: giraffe (Giraffa camelopardalis), nyala, kudu, bushbuck (T. scriptus), blesbok, blue wildebeest, hartebeest (Alcelaphus buselaphus), waterbuck (Kobus ellipsiprymnus), gemsbok, zebra (E. zebra) and common duiker (Sylvicapra grimmia).

The seemingly relaxed nature of the meat trade may mean that not all substitutions of native game with other game were intentional. In addition, most shops display biltong in open baskets, and the misplacing of labels cannot be discarded. Nevertheless, the substitutions with domestic animals, kangaroo and game meat normally

Table 1 Extent of substitutions summarized by product type

\begin{tabular}{llll}
\hline Sample type & $\mathbf{N}$ & False & Percentage substitution \\
\hline Biltong & 94 & 65 & 69.15 \\
Carpaccio & 6 & 2 & 33.33 \\
Dry sausage & 29 & 25 & 86.21 \\
Fresh sausage & 2 & 1 & 50.00 \\
Mince and fresh & 10 & 5 & 50.00 \\
Smoked & 5 & 3 & 60.00 \\
Total & $\mathbf{1 4 6}$ & $\mathbf{1 0 1}$ & $\mathbf{6 9 . 1 8}$ \\
\hline
\end{tabular}

$\mathrm{N}=$ number of samples. 
absent from the market (for example, giraffe) cannot be attributed to human error but must be regarded as intentional. Given the richness of antelopes and other bovids in South Africa, the limited number of species in the market is surprising, likely due to a commercial simplification of choices for consumers with poor wildlife knowledge.

\section{Validation of species identifications}

A simple similarity value is meaningless unless the range of variation within the class is known. We followed different methods to estimate the reliability of our assignments. The assignments were considered correct when the BLAST similarity value score was $100 \%$, and the query sequence belonged to monophyletic clusters with high bootstrap support (Figure S1a-r in Additional file 3). All cytb and COI sequences obtained in this study showed identities higher than 97\% with existing sequences in the GenBank database (Table S2 in Additional file 2).

The intraspecific and interspecific range of genetic variation was plotted for all identified native African groups except ostrich (Figure 1a,b). Genetic variation within and between species that do not conform to published recommendations [17,21-23] for species delimitation are discussed in the following section for each case.

Phylogenetic trees were not shown when scarce information was available (Giraffidae, Suidae and Macropodidae $\mathrm{COI}$ ) or for trees with similar information to that recovered by cytb (Bovini, Caprini). The BLOG classes that identified query and test DNA fragments correctly with $100 \%$ efficiency are shown in the phylogenetic tree figures. Incorrect assignments occurred when data contained insufficient information or the availability of references to test sequences did not reach the required 4:1 proportion.

Below we present the evaluation of species identifications for each group, and discuss the results in view of the known variation and evolutionary history of each group.

\section{Bovidae: Antilopinae: Aepycerotini}

This tribe is represented by one monotypic genus, represented by the impala Aepyceros melampus, with two subspecies with disjunct distribution: A.m. petersi and $A . m$. melampus. It is a very common species in the grasslands and bushlands of eastern south-central and southeastern Africa. Two out of the four samples labeled 'impala' were correct, and was found as substitute for other game.

The genetic identification of this species would not pose any concern as it appears basal to Antilopini [40], with large sequence divergence from its relatives [40].
The COI phylogenetic tree is shown in Figure S1a in Additional file 3.

Both cytb and D-loop detect continental and regional (South Africa) phylogeographic structure respectively $[43,44]$. The COI phylogenetic tree reflects a similar continental pattern to that of cytb [43]. However, the frequent translocations of this species in South Africa (see below) would hamper the inference of local geographic origin of samples.

\section{Bovidae: Antilopinae: Antilopini}

This tribe is represented by gazelles, which inhabit open semiarid environments in Africa and Eurasia. Springbok is one of the most abundant antelopes in southern Africa. It was found mostly substituted (76\%) with domestic, foreign or other game species and as a substitute for ostrich (Table 2).

The maximum sequence variation observed for this species was $2 \%$ for cytb and $0.6 \%$ for COI. For the scarce information available, these values should be taken with caution. The COI phylogenetic tree is shown in Figure S1a in Additional file 3.

\section{Bovidae: Antilopinae: Alcephalini}

Four genera compose this tribe of grazers, herd antelopes: Alcelaphus, Beatragus Connochaetes and Damaliscus; only Beatragus does not occur in southern Africa.

Damaliscus pygargus are distinctive white-faced antelopes endemic to South Africa, divided into subspecies by geographic range: bontebok in coastal fynbos and blesbok in the Highveld. The bontebok has recovered to a current number of approximately 3,500 animals with a consequent change of their IUCN status 'vulnerable' to 'near threatened' in 2008. One out of two collected samples of blesbok was correct, and it was found as a substitute for other game (Table 2).

The information contained in cytb and COI fragments did not allow for subspecies resolution with either the phylogenetic or the character-based methods (Figure S1b,c in Additional file 3), possibly because of incomplete lineage sorting or hybridization. D-loop was reported to distinguish these two forms [45]. The original discontinuous geographic distribution of these forms has been blurred by translocations to private land and other anthropogenic activities bringing them into secondary contact, resulting in hybridization. Therefore, for food validation purposes, the identification at the subspecies level may imply an unnecessary effort.

The hartebeest was found as a substitute for other game. Flagstad et al. [46] identified two major continental lineages with D-loop and cytb, which would allow for inference of geographic origin of samples at continental level. The cytb phylogenetic analysis shown in Figure S1b in Additional file 3 indicates the identity of our samples 


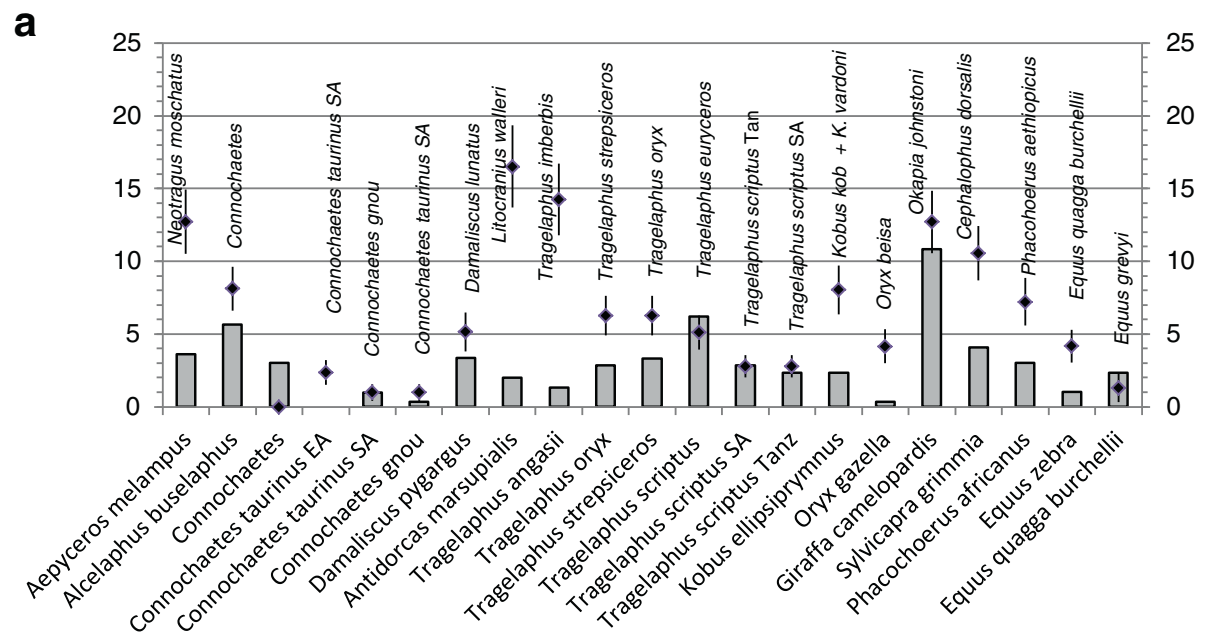

b

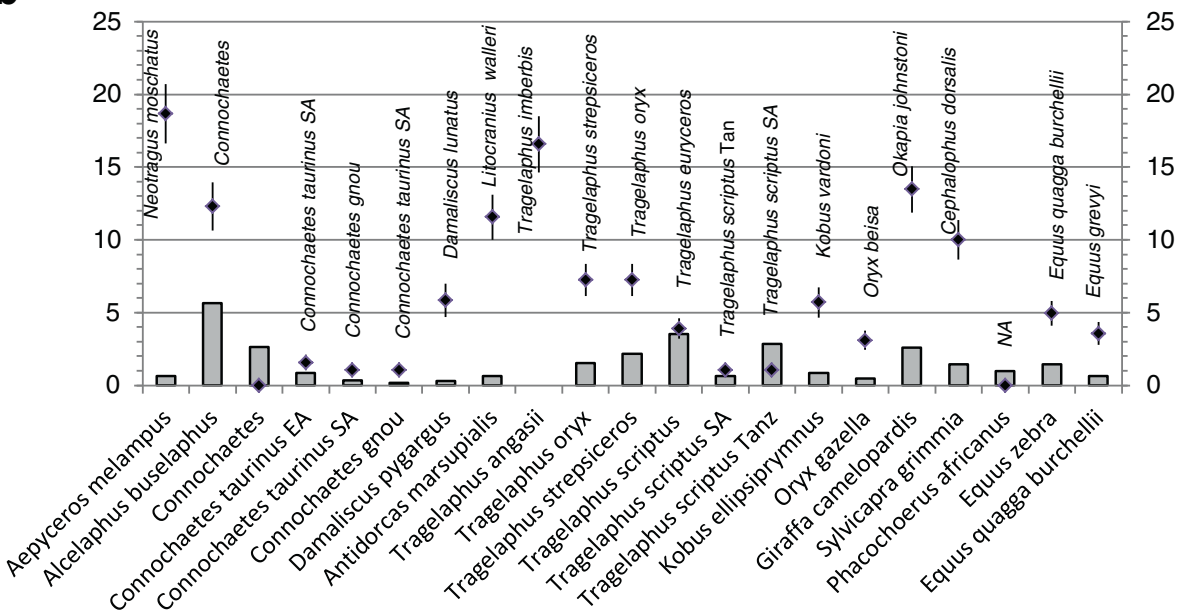

Figure 1 Kimura 2-parameter distances $(\times 100)$ observed within and between species. (a) Maximum observed cytochrome b Kimura 2parameter (K2P) distance within species are shown in histograms, bars indicate the net between-species K2P divergence from the phylogenetically closest related species. (b) Maximum observed cytochrome c oxidase subunit I K2P distance within species are shown in histograms, bars indicate the net between-species K2P divergence from the phylogenetically closest related species. NA: Not available, SA: South Africa, Tan: Tanzania.

with $A$. $b$ caama; incomplete taxa availability for COI forces our sequences to cluster with $A$. $b$. lichtensteinii (Figure S1c in Additional file 3). BLOG results show 100\% efficiency assignment to A. buselaphus with cytb and one element remained not classified for a polymorphism in a 'diagnostic' site (Figure S1b in Additional file 3).

The black wildebeest is endemic to southern Africa, whereas the blue wildebeest occurs in eastern and southern Africa. They display morphological, behavioral and ecological differences. Wildebeest was found substituted by and substituting for other game species (Table 2). The low genetic variation observed for the genus falls within that observed for other within-species values (Figure 1a,b). These results are evidence of a very recent speciation event. In addition, the black wildebeest experienced extensive hunting and habitat reduction that resulted in a drastic reduction of its population size [ 40 and references therein]. Its IUCN status was 'vulnerable' until 1994, but since 2002 it is considered of 'no concern'. Despite its recovery, the important reduction in population size is still reflected in the low level of genetic variation found in cytb and COI fragments.

Using D-loop, significant phylogeographic structure has been detected for the blue wildebeest, with clusters specific to eastern Africa and southern Africa [47]. Our phylogenetic analyses with cytb and COI showed a similar geographic dichotomy, with its southern form being more closely related to the black wildebeest. BLOG recovered complete assignments for both species with 
Table 2 Substitutions found for meat products with cytb and COI DNA sequence information

\begin{tabular}{|c|c|c|c|c|c|c|c|c|}
\hline \multirow[b]{2}{*}{$\begin{array}{l}\text { Commercial } \\
\text { label }\end{array}$} & \multirow[b]{2}{*}{ Species } & \multirow[b]{2}{*}{$\mathbf{N}$} & \multirow[b]{2}{*}{ Correct } & \multirow[b]{2}{*}{ False } & \multicolumn{2}{|c|}{ Substituted samples } & \multirow[b]{2}{*}{$\begin{array}{l}\text { Other species found in } \\
\text { non-mixed samples }\end{array}$} & \multirow[b]{2}{*}{$\begin{array}{l}\text { Species found in mixed } \\
\text { samples (sausages) }\end{array}$} \\
\hline & & & & & $\begin{array}{l}\text { Substituted } \\
\text { with beef }\end{array}$ & $\begin{array}{l}\text { Mixture of } \\
\text { species }\end{array}$ & & \\
\hline Beef & Bos taurus & 14 & 14 & 0 & NA & 1 & NA & \\
\hline Blesbok & $\begin{array}{l}\text { Damaliscus } \\
\text { pygargus }\end{array}$ & 2 & 1 & 1 & 0 & 0 & Bushbuck & - \\
\hline $\begin{array}{l}\text { Blue } \\
\text { wildebeest }\end{array}$ & $\begin{array}{l}\text { Connochaetes } \\
\text { taurinus }\end{array}$ & 1 & 0 & 1 & 0 & - & Nyala & - \\
\hline Eland & Tragelaphus oryx & 8 & 1 & 7 & 2 & - & Gemsbok, kudu, blue wildebeest, & - \\
\hline Game & Game & 5 & 2 & 3 & 3 & 0 & Gemsbok & - \\
\hline Gemsbok & Oryx gazella & 14 & 4 & 10 & 3 & - & $\begin{array}{l}\text { Kudu, blesbok or bontebok, blue } \\
\text { wildebeest, impala }\end{array}$ & - \\
\hline Impala & Aepyceros melampus & 4 & 2 & 2 & 1 & - & Bontebok or blesbok & - \\
\hline Kudu & $\begin{array}{l}\text { Tragelaphus } \\
\text { strepsiceros }\end{array}$ & 39 & 3 & 36 & 13 & 5 & $\begin{array}{l}\text { Hartebeest, gemsbok, waterbuck, } \\
\text { eland, mountain zebra, giraffe, } \\
\text { lamb, kangaroo }\end{array}$ & $\begin{array}{l}\text { Kangaroo }+ \text { beef, } \\
\text { beef }+ \text { lamb, eland }+ \\
\text { hartebeest }\end{array}$ \\
\hline Ostrich & Struthio camelus & 23 & 7 & 16 & 10 & 5 & $\begin{array}{l}\text { Springbok, kudu, black wildebeest, } \\
\text { kangaroo }\end{array}$ & $\begin{array}{l}\text { Ostrich + lamb, beef }+ \\
\text { pork, beef }+ \text { lamb }\end{array}$ \\
\hline Springbok & $\begin{array}{l}\text { Antidorcas } \\
\text { marsupialis }\end{array}$ & 33 & 8 & 25 & 11 & 4 & $\begin{array}{l}\text { Gemsbok, kudu, eland, blue } \\
\text { wildebeest, hartebeest, impala, } \\
\text { common duiker, kangaroo, horse }\end{array}$ & $\begin{array}{l}\text { Beef }+ \text { waterbuck, } \\
\text { beef }+ \text { lamb, springbok } \\
+ \text { lamb }\end{array}$ \\
\hline Warthog & $\begin{array}{l}\text { Phacochoerus } \\
\text { africanus }\end{array}$ & 2 & 2 & 0 & 0 & 0 & - & - \\
\hline Zebra & Equus burchelli & 1 & 1 & 0 & 0 & 0 & - & - \\
\hline Total & & 146 & 45 & 101 & 43 & 15 & & \\
\hline
\end{tabular}

The number of substituted products in the form of species mixtures is indicated in the column 'Mixture of species', and the nature of these mixtures are indicated under "Species found in mixed samples (sausages)". The substitutions for biltong, fresh meat, carpaccio and smoked meat are summarized under 'Other species found in non-mixed samples"'. "Substituted with beef" is indicated for both mixed and non-mixed samples. Domestic and foreign substitute species are indicated in bold. NA: not applicable.

COI information and assignment to a single class containing all Connochaetes cytb sequences.

Hybridization between wildebeest species is known in South Africa as a result of anthropogenic transloca tions beyond their natural geographic range [48]. This phenomenon is reflected among our reference South African blue wildebeest samples, which cluster with black wildebeest (Figure S1c in Additional file 3). Therefore, for food identification purposes, wildebeest should be certified only at the level of genus in southern Africa.

\section{Bovidae: Antilopinae: Caprini}

Lamb was found in kudu biltong, in ostrich and springbok droë wors, and mixed in venison (springbok) mince. Phylogenetic trees with other caprini showed a monophyletic cluster with high bootstrap support for our samples (Figure S1d in Additional file 3).

\section{Bovidae: Bovinae: Bovini}

All samples labeled beef were correct. However beef was found present in $32 \%$ of samples labeled as some form of game.

The cytb and COI phylogenetic trees with other bovini showed a monophyletic cluster with high bootstrap support for our samples. The cytb tree is shown in Figure S1e in Additional file 3.

\section{Bovidae: Bovinae: Tragelaphini}

Tragelaphini is a tribe of spiral-horned, large antelopes. Kudu inhabits eastern and southern Africa; 92\% of the kudu samples were substituted with domestic, foreign or other game species (Table 2).

Our cytb BLAST searches identified high similarity to entries [GenBank:L13794.1] and [GenBank:L13793.1], submitted as Bubalus depressicornis, an Indonesian buffalo species. The phylogenetic reconstruction of Figure S1f in Additional file 3 and BLOG assignments confirmed the identity of [GenBank:L13794.1] to kudu and [GenBank: L13793.1] to eland.

The maximum within-species variation was $3.293 \%$ for cytb and $2.183 \%$ for COI (Figure 1a,b), exceeding the average divergence within-species values indicated by Tobe et al. [22]. Phylogenetic trees show kudu sequences arranged into two clusters, corresponding to eastern and southern Africa. In turn, the southern African sequences are arranged in two clusters. Nersting and Arctander [43] showed continental phylogeographic 
structure with D-loop analysis. Unfortunately, no samples from South Africa were used in this study.

The eland is a very large antelope species, with males reaching $600 \mathrm{~kg}$. It inhabits savannahs and grasslands of eastern and southern Africa. Only one out of the eight eland samples was correct. This species was substituted with beef and other game, and was utilized as a substitute of other game species (Table 2). Similarly to the results for kudu, eland sequences are arranged in two clusters corresponding to eastern and southern Africa (Figure S1f,g in Additional file 3). This structure was previously observed using D-loop sequence information [49].

The nyala is endemic to southeastern Africa where it inhabits forests and woodlands close to water. This species was found as a substitution for blue wildebeest. Very little information is available for this species, thus the values in Figure 1 should be taken with caution. A significant population structure was detected using microsatellites and D-loop [50], which could potentially be used to infer the geographic origin of samples.

The bushbuck is a browser species, widely distributed in forests and bushlands on the continent. This species was found as a substitute for blesbok. The differential clustering of the southern African and Cameroonian bushbuck (Figure S1f,g in Additional file 3) is due to the known paraphyly of this group [51]. Hassanin et al. [40] suggested they should be considered different species.

Figure S1a,b in Additional file 3 shows an inflated within-species variation because it is composed of two different taxonomic units. To account for this taxonomic problem, we plotted the within-species variation for $T$. scriptus from South Africa and Tanzania separately (Figure 1). Notwithstanding the overlapping withinbetween species genetic distance, the phylogenetic trees clearly distinguished them. BLOG recognized three classes with $100 \%$ efficiency for cytb data, but recognized one single bushbuck class with COI data.

\section{Bovidae: Bovinae: Hippotragini}

This tribe is composed of genera Hippotragus (saber and roan antelopes), Addax and Oryx. The four Oryx species inhabits semi-desert areas. The southern African oryx or gemsbok is found in South Africa and Namibia.

Most gemsbok samples were substituted with beef and other game, and it was also found as substitute for other game species (Table 2). A surprisingly low level of genetic variation seems to be harbored by this species (Figure 1), with one variable site for cytb and six for COI. The phylogenetic trees in Figure S1h,i in Additional file 3 show an odd clustering for JN869311 (Oryx dammah), which is likely an erroneous submission of Addax nasomaculatus. BLOG identifies $A$. nasomaculatus cytb as a wrongly classified element to its training class, but no misclassification was detected in the $\mathrm{COI}$ training classes.
BLOG recovered complete assignment for all the samples of $O$. gazella except for cytb sequence [GenBank:JX567271] because of an ambiguity in the identified diagnostic site for O. gazella (site 14259 in genome [GenBank:JN632678]). From a forensic perspective, this sample cannot be excluded from O. gazella.

\section{Bovidae: Bovinae: Reduncini}

This is a tribe of grazers associated with marshes and waterlands. It is composed of three genera: the monotypic Pelea, Redunca and Kobus. Of the six Kobus species, only the common waterbuck $K$. ellipsiprymnus ellipsiprymnus inhabits South Africa, and was found as a substitution for other game. The waterbuck displays parapatric geographic distribution with the defassa waterbuck $K$. e. defassa with an overlap in eastern Africa, where hybridization has been reported [52].We estimated the K2P distance between $K$. ellipsiprymnus and $K . k o b+K$ vardoni as the latter is internal to the $K$. $k o b$ cluster for cytb sequences (Figure S1j in Additional file 3). Interspecific COI K2P distance was estimated using only $K$. vardonii because of the unavailability of K. kob.

The phylogenetic reconstructions in Figure $S 1 j, k$ in Additional file 3 seem to reflect geographic origin. BLOG identified three classes within K. ellipsiprymnus with full correspondence with the cytb phylogenetic tree. Higher resolution is obtained with BLOG than with the ML tree for $K$. vardoni and $K$. kob.

\section{Bovidae: Antilopinae: Cephalophini}

This is a tribe of small antelopes with small horns know as duikers, which mostly inhabit forests. The common duiker was found in our samples as a substitute for springbok. This duiker species is ubiquitous in the sub-Saharan African continent, being absent only in rainforest areas and the horn of Africa. Sylvicapra was referred as monotypic [53] but recently shown to cluster within the giant Cephalophus duikers (C. dorsalis, C. jentinki, C. silvicultor and C. spadix) when using a multilocus phylogenetic approach [54], thus making Cephalophus paraphyletic. Similar results were obtained with whole mitochondrial sequence information by Hassanin et al. [40].

Johnston et al. [27] detected COI genetic distances below 3\% between some Cephalophus species for their recent speciation processes estimated at $\leq$ one million years ago [54]. The interspecific distances for the common duiker shows an earlier speciation event, estimated at approximately 5.6 million years ago [27] (Figure 1).

The phylogeographic structure may account for the large cytb intraspecific distance observed in the common duiker (Figure 1a). 
BLOG indicated $100 \%$ assignment to all training classes, identified the paraphyletic $C$. callipygus as a single class (Figure S1l in Additional file 3), and assigned the test sample to the common duiker class. In COI data analysis, one $C$. ogilbyi training element was recognized as a false positive due to limited information in the dataset, because of its recent evolutionary history [27]. The test sample remained unassigned because of an ambiguity in a diagnostic site. In forensic practice, this sequence cannot be excluded from 'common duiker' class (Figure S1m in Additional file 3).

\section{Giraffidae}

This family is composed of long-necked giraffes and okapis. The nine known Giraffa camelopardalis subspecies are widely distributed on the continent. The southern African G. c. giraffe is the only subspecies found in South Africa. Giraffe was found as a substitute for kudu biltong.

Brown et al. [55] and Hassanin et al. [56] studied the phylogeography of Giraffa using 1,143 and 1,765 bp mtDNA fragments respectively, encompassing cytb. Both studies identified strong phylogeographic structure in the continent. Brown et al. [55] argued that these subspecies should be considered separate species. The intraspecific maximum genetic distance in giraffes is unmatched (Figure 1a).

Our phylogenetic reconstruction shows the Angolan giraffe G. c. angolensis (Angola and Namibia) and the southern African giraffe (South Africa and Zimbabwe) sequences in a single cluster as a result of insufficient information in our shorter cytb fragment. There is insufficient information in this fragment to identify subspecies (Figure $\mathrm{S} 1 \mathrm{n}$ in Additional file 3). BLOG found false negative and/or false positives in all training classes except for G. c. peralta, G.c. reticulata and G.c. antiquorum and the test sample is assigned only at the species level.

\section{Suidae}

Suidae is a family composed of pigs. The warthogs Phacochoerus are widely distributed sub-Saharan African wild pigs, represented by two disjunct subspecies: the common ( $P$. africanus africanus) and the Ethiopian warthog ( $P$. a. aethiopicus).

The two samples labeled warthog were correctly labeled whereas domestic pork was identified in an ostrich droë wors.

The monophyly of African pigs [57] (Phacochoerus, Hylochoerus and Potamochoerus) was not maintained when using the short cytb fragment used in this study. Therefore we used complete cytb sequence information recovered from GenBank along with our partial cytb fragments, applying partial deletion for missing data for phylogenetic reconstruction (Figure S1o in Additional file 3).

The two clusters observed for the common warthog correspond to geographic distribution. Continental phylogeographic structure was reported for this species with D-loop [58].

The phylogenetic reconstruction also shows an unusual clustering of the entries for Sus celebensis [GenBank: AY534298.1], Potamochoerus porcus [GenBank:AY534299.1] and Potamochoerus larvatus [GenBank:AY534300.1]. These are likely erroneous submissions. BLOG was run using the short cytb fragment dataset. Assignment classes for the test sequences were defined with $100 \%$ efficiency, no false positives or unassigned elements were detected in any speciesdefined class.

\section{Equidae}

This Perissodactyla family is composed of horses, donkeys and zebras. One sample labeled 'zebra' was indeed the mountain zebra E. zebra, whereas Burchell's zebra and horse were found as substitutes for other game.

The study of the phylogenetic relationship of Equus species was been hampered by recent speciation processes, incomplete lineage sorting and introgression. Steiner et al. [59] resolved the phylogenetic relationship between zebra species using two mtDNA and 20 nuclear genes. Approximate tree topologies were recovered by our cytb and COI trees (Figure S1p,q in Additional file 3). Higher bootstrap supports were obtained for COI, but cytb can distinguish the two subspecies of cape mountain zebra E. z. zebra and Hartmann's mountain zebra E. z. hartmannae that inhabit South Africa and Namibia, respectively. The tree in Figure S1p in Additional file 3 shows our sample \#27 as Hartmann's zebra. BLOG showed $100 \%$ efficiency to class (species) assignment.

The mountain zebra E. zebra suffered from severe reduction in population size in South Africa. The Mountain Zebra National Park hosted 19 mountain specimens at the time of its foundation in 1935. By then, only five other remnant populations were known in South Africa, where, unsurprisingly, strong population structure was detected using D-loop and microsatellites [60]. By contrast, the plains zebra showed no evidence of population structure [61].

\section{Macropodidae}

Kangaroo species were found as substitutes for six other game species. The low similarity of [GenBank:JX567266] to $M$. robustus is due to sequence ambiguities. However BLOG shows this sample as unassigned and all assignment classes (species) are defined with 100\% efficiency. 
COI sequences were obtained both with universal and Macropus-specific primers designed in this study. Because of the currently limited COI entries for Macropodidae, identification with COI is only valid at the genus level, and four samples remained unassigned. The similarity of [GenBank:JX567041] to Lagorchestes hirsutus, a wallaby species (Table S2 in Additional file 2) is a clear example of anerroneous result because of incomplete information in databases.

\section{Aves: Struthioniformes: Struthionidae}

Ostrich was mostly found substituted (76\% samples), by beef, kangaroo and other game (Table 2).

Population genetic data are only available for the mtDNA control region, which elucidated continental phylogeographic structure [62].

\section{Conclusions}

\section{The practical problem of species delimitations}

In forensics, it is important to provide an indication of the reliability of identification. It is beyond the scope of this paper to discuss the problems of species classification but rather we shall evaluate the methods of assignment for their application to wildlife or food forensics. All sequences were identified at subspecies, species or genera level for their high similarity to either vouchers or multiple entries in databases, monophyly with high bootstrap support, or full assignment to defined classes (subspecies, species, genus). The consistency in results obtained with methods based on different theoretical foundations demonstrates the reliability of the identifications.

The combined application of methods highlighted each of their strengths and weaknesses. Possibly the most important limitation affecting all methods is the incomplete within-species and taxa representation in databases. The African continent displays the highest diversity of ungulates on the planet, yet many species are poorly represented in databases. Phylogeographic structure at continental level and connectivity between east and southern Africa is common to many taxa because of the similar effects of Pleistocene climatic changes (see [63] and references therein). Most of these studies were conducted with the faster mutating control region. The geographic origin of samples on a large scale can still be inferred using cytb or COI fragments. In South Africa, the translocation of fauna is a natural consequence of the increasing ranching and private nature reserve activities. The species that are most frequently transferred outside their natural geographic limits are eland, gemsbok, blesbok, Burchell's zebra and impala [64]. Therefore, geographic origin should be considered with caution for species with local population structure.

Incomplete geographic sampling of a species would determine underestimation of within-species genetic variation, and recent speciation processes would reflect shallow genetic distances between species, and often overlapping within-species variation. The latter case was evidenced for the South African and Tanzanian bushbucks. However, phylogenetic analysis allows for identification of these 'overlapping' forms, which show reciprocal monophyly.

Overlapping inter-intra species variation along with incomplete lineage sorting and absence of reciprocal monophyly was detected in Connochaetes (gnous), and in Damaliscus pygargus. D-loop seems to be more informative for both groups [45,47] (although paraphyly was described for blue wildebeest [47]). In addition, hybridization has been reported. Certainty can therefore be achieved at genus level for wildebeest in South Africa.

In general, similar results were recovered by the $\mathrm{ML}$ phylogenies and BLOG. The efficiency of BLOG is more reliant on the availability of large reference data. Nevertheless, its performance in limiting reference data conditions was similar to that of the phylogenetic approach. An exploratory phylogenetic analysis prior to the application of character-based methods would be advisable in the light of possible erroneous submissions to databases. Our phylogenetic analysis detected anomalous submissions to GenBank for Tragelaphini, Hippotragini and Suidae. BLOG showed full assignment for all our test sequences to predefined classes of species or even subspecies. Some elements identified as 'unassigned' for Alcelaphini, Cephalophini and Macropus required a 'non-exclusion' category applying forensic criteria. For the erroneous GenBank submission identified with ML, BLOG misidentified the erroneous sequence for Hippotragini cytb and did not detect COI classes with wrong elements. BLOG outperformed ML in the identification of Cephalophini cytb classes.

\section{Technical recommendations}

In several mixtures it was not possible to generate readable sequences with both cytb and COI fragments (for example, lamb was detected with COI preferentially over beef and ostrich). Differential affinity for different species might explain these results. We obtained DNA from two to four different approximately $1 \mathrm{~mm}^{2}$ dissected fragments per sausage and therefore the presence of additional species cannot be discarded. A technical approach such as next generation sequencing would allow identifying other 'alleles' in the samples. A more affordable, though laborious, option is the standard PCR approach followed by Sanger sequencing followed by BLAST and phylogenetic analysis. A probe-based approach is not recommended at present for wildlife forensic applications because of the vast volume of uncovered genetic diversity on the continent. 


\section{Commercial, political and religious implications of our results}

The implications of our results have direct impact on the sensitivity of consumers. The avoidance of pork has serious religious connotations for the local Jewish and Muslim communities. The discovery of game substituted by kangaroo has an important social impact in Namibia as the local regulations do not support imported products being supplied to state institutions [65]. The consumer should have the right to choose over correctly provided information. A change in the labeling system to indicate generic 'game' should be clearly distinguished from appropriately indicated domestic or foreign species.

\section{Endnotes}

${ }^{a}$ Burchell's zebra (Equus quagga burchelli) is a variety of the plains zebra E. quagga. It is often referred to as $E$. burchelli, or even E. burchellii quagga.

\section{Additional files}

Additional file 1: Table S1. GenBank accession numbers of cytb and COl sequences used in the estimation of K2P shown in Figure 1, phylogenetic analyses and BLOG analysis shown in Table S2 in Additional file 2. In bold: reference sequences generated in this study.

Additional file 2: Table S2. Summary of species identification results for cytb and COI sequences obtained from commercial meat products. The maximum sequence similarity with GenBank entries is provided in \% identity, along with the phylogenetic tree bootstrap support for the species or subspecies clusters. BLOG assignments to defined classes: 100; $U$ : unassigned elements.

Additional file 3: Consensus Maximum Likelihood trees constructed using Kimura 2-parameter model and 1,000 bootstrap replicates.

Branches corresponding to partitions reproduced in less than $50 \%$ bootstrap replicates are collapsed; bootstrap support is shown on the nodes. Substitutions are shown in red with the sample ID and species indicated by the commercial label. Species names are kept as the original submissions to GenBank. When known, the specimen geographic origin is indicated: Aby: Abyssinia; BNP: Bontebok National Park; Cam: Cameroon; CAR: Central African Republic; Chad: Chad; E Africa: East Africa; Gui: Guinea; Ken: Kenya; Ma: Mali; MZNP: Mountain Zebra National Park; Niga: Nigeria; Niger: Niger; NZG: National Zoological Gardens; SA: South Africa; Sau: Saudi Arabia; So: Somalia; Tan: Tanzania; Uga: Uganda; Zam: Zambia; Zim: Zimbabwe. Colored blocks indicate clusters defined with $100 \%$ assignment efficiency by BLOG. Substitutions are shown in red, food samples ID can be found in Table S2 in Additional file 2. Figure S1a Aepycerotyni and Antilopini COI sequences. ML Tree Log $=-2234.00$. Figure S1b. Alcelaphinae cytb sequences. ML Tree $\log =-1510.45$.** element not assigned to any class. Figure S1c. Alcelaphini COI sequences. Tree $\log L=-1252.20$. Figure S1d. Caprini COI sequences. Tree $\log L=-2008.41$. Figure S1e. Bovini cytb sequences. Tree $\log L=$ -1134.75. Figure S1f. Tragelaphini cytb sequences. * erroneous submission to GenBank. T. eurycerus: JN632703, AF036276, AF022065; T. spekii: EF536357, AJ222680; T. buxtoni: AY667215-216; Tree LogL = -2153.35 . BLOG recovered classes with fully assigned (either test or training) elements, which are indicated with colored boxes. Training classes defined for all other species contained 100\% assigned elements. Figure S1g. Tragelaphini COI sequences. Tree LogL $=-2146.42$. BLOG recovered classes with fully assigned elements, which are indicated with colored boxes. Uncolored boxes: other defined training classes with correct classified elements. Figure S1h. Hippotragini cytb sequences. Tree LogL $=-1020.96 .{ }^{*}$ erroneous submission; ** BLOG wrong classified element. Oryx beisa GenBank entries are JN632676.1, DQ138192.1-210.1;
HM209249.1. Figure S1i. Hippotragini COI sequences. Tree LogL = -1874.32. * possible erroneous submission. Figure S1j. Reduncinae cytochrome $b$ sequences. Tree $\log \mathrm{L}=-1387.71$. BLOG recovered classes with fully assigned (either test or training) elements, which are indicated with colored boxes. Training classes defined for all other species contained 100\% assigned elements. Figure S1k. Reduncinae COI sequences. Tree Log $L=-1501.5$. BLOG recovered classes with fully assigned (either test or training) elements, which are indicated with colored boxes. Training classes defined for all other species contained 100\% assigned elements. Figure S1I. Cephalophinae cytb sequences. Tree LogL $=-2206.5$. Cephalophinae cytb GenBank accession numbers for Philatomba maxwelli are JN632885, AF096629.1, AF153894.1; for P. monticola are JN632686, JN632687, AF153891.1- 893.1; for Cephalophus dorsalis are JN632615.1; AF153884.1, AF091634; for C. silvicultor AF153898.1, JN632622.1; for C. spadix are AF153899.1, JN632623.1; for C. callipygus are AF153885-86, JN632613-14; for C. leucogaster are JN632617.1, AF153889.1; for C. nigrifrons are JN632619.1, AF153886.1; for C. rufilatus are JN632621.1, AF153901.1, for C. natalensis are JN632618.1, AF153890.1, for C. harveyi are FJ959388.1, AF153887.1 and for C. adersi are JN632611.1, AF153883.1. All classes defined by BLOG correspond to nominated species. In colored boxes: the class for the test sample \#53, Sylvicapra grimmia, and the separate classes identified for C. callipygus and C. ogylbyi. Figure S1m. Cephalophinae COI sequences.

Cephalophinae cytb GenBank accession numbers for Cephalophus dorsalis are JN632615.1; HQ644091.1, HQ644092.1; GQ144507.1- 514.1; for C. nigrifrons are GQ144446.1-450.1; C. rufilatus are JN632621.1, HQ644111.1; for C. leucogaster are JN632617.1, GQ144515.1-521.1; HQ644095.1-968.1; for C. niger are HQ644105-106.1; for C. callipygus cluster (1) are JN632612.1, GQ144485.1, GQ144486.1, GQ144491.1, GQ14492.1, GQ144498.1, GQ144499.1, GQ144504.1, HQ644089.1, HM144023, HM144025; for C. callipygus cluster (2) are JN632614.1, GQ144483.1, GQ144487-489.1, GQ144493-495.1, GQ144500-503.1, GQ144505.1, HQ644090.1, HQ644109.1; for C. adersi are HQ644086.1, HQ644087.1; for Philatomba monticola cluster (1) are JN632887, HQ644101.1; for $P$. monticola cluster (2) JN632686, GQ144522-533.1, GQ144535.1, GQ144540.1, GQ144543.1, GQ144544.1; for Philatomba maxwelli are JN632685, HQ644099.1, HQ655100.1. Tree LogL $=-3675.85$. ** BLOG not classified sequences; ${ }^{* * *}$ BLOG erroneously classified sequence. Colored box indicates the BLOG class defined class for S. grimmia. Figure S1n. Giraffidae cytb sequences. The GenBank accession number for cluster (1) are EU088326.1- EU088328.1, EF442273.1; for cluster (2) are EF442274.1, EU088317.1-EU088317.1; for cluster (3) are JN632645.1, EF442265.1EF442268.1; for cluster (4) are EU088319.1, EU088320.1, EU088322.1EU088325.1, EU088334.1; for cluster (5) are AY534342.1, EU08331.1, EU088333.1; for cluster (6) DQ470781.1, EF442269.1, EF442270.1, EF442271.1 from Limpopo, South Africa, EU088329.1, EU088330.1 EU088332.1, EU088335.1-EU088344.1; for cluster (7) are EU088345.1EU088351.1, EF442263.1, EF442264.1, AP003424.1, NC_012100.1; for cluster (8) are EU088352.1, AF181470.1, AY121933.1. Tree LogL = -879.10. Figure S1o. Suidae whole cytb sequences (1140 bp). The bootstrap values were inferred from 1,000 replicates. Tree LogL $=-6959.31$. The GenBank accession numbers for cluster (1) are GQ338962.1, AY534297.1, AJ314554.1, AJ314555.1, AM492658-662; for cluster (2) are GQ338963.1, AJ314553.1; for cluster (3) are NC_000845, NC_012095.1, NC_014692.1, AY692029.1, for cluster (4) are AM492663-665, GQ338964.1. * erroneous submission to GenBank. Assignments (classes) defined by BLOG with $100 \%$ efficiency are shown with colored boxes. Figure S1p. Equidae cytb sequences. Tree Log $L=-1,000.63$. The GenBank accession numbers for Equus assinus are FF18884, NC001788, FJ428492, FJ428526 and E. a. somalicus FJ428508. BLOG assignment classes are shown in colored blocks. Figure S1q. Equidae COl sequences. Tree $\log \mathrm{L}=-1870.39$. Figure S1r. Macropodidae cytb sequences. Tree Log $\mathrm{L}=-1665.38$. BLOG classes are shown in colored boxes. ${ }^{*}$ unassigned sample.

\section{Abbreviations}

BLAST: Basic Local Alignment Search Tool; BOLD: Barcode of Life Data Systems; Bp: Base pairs; CITES: Convention on International Trade in Endangered Species of Wild Fauna and Flora; COl: cytochrome c oxidase subunit l; cytb: cytochrome b; IUCN: International Union for Conservation of 
Nature; K2P: Kimura-2-parameter; ML: maximum likelihood; mtDNA: mitochondrial DNA; PCR: polymerase chain reaction.

\section{Competing interests}

The authors declare that they have no competing interests.

\section{Authors' contributions}

MED proposed the experimental design and performed the data analysis; MED and SD wrote the manuscript; KWC, SD and MED performed the sampling; KWC, EA and DC generated the data; DC proposed the original idea. All authors read and approved the manuscript.

\section{Acknowledgements}

We gratefully acknowledge the assistance of Cathy Dreyer from South Africa National Parks, Desiree Dalton and Antoinette Coetze from the National Zoological Gardens, Eric Harley and Steven Mitchell from the Quagga Project Association for providing reference samples for this study; Giovanni Felici for discussions on BLOG; Liz Scott (American Museum of Natural History) for critical reading of the manuscript, and the anonymous reviewers for their valuable comments and suggestions to improve the manuscript. DC is a member of the Research Career and EA a doctoral fellowship of CONICET (National Research Council) of Argentina. This project was funded by the NRF KISC grant UID: 69795 and UWC SNS funds.

\section{Author details}

${ }^{1}$ Biotechnology Department, Forensic DNA Lab, University of the Western Cape, Modderdam Road, Bellville 7535, South Africa. ${ }^{2}$ Servicio de Huellas Digitales Genéticas, School of Pharmacy and Biochemistry, University of Buenos Aires, Junín 956, 1113, Buenos Aires, Argentina.

Received: 29 November 2012 Accepted: 14 February 2013 Published: 1 March 2013

\section{References}

1. Paleari MA, Camisasca S, Beretta G, Renon P, Corsico P, Bertolo G, Crivelli G Ostrich meat: physico-chemical characteristics and comparison with turkey and bovine meat. Meat Sci 1998, 48(3/4):205-210.

2. Carruthers J: Wilding the farm or farming the wild? The evolution of scientific game ranching in South Africa from the 1960s to the present. T Roy Soc S Afr 2008, 63:160-181.

3. Hoffman LC, Muller M, Schutte De W, Crafford K: The retail of South African game meat: current trade and marketing trends. S Afr J Wild Res 2004, 34:123-134.

4. Dry G: Wildlife ranching in perspective. Wildlife Ranching 2011, 4(3):24-27. http://www.wrsa.co.za/wrsa-e-magazine/book/5-summer-2011-publication/ 2-wrsa-publications.

5. Saayman $M$, van der Merwe $P$, Rossouw $R$ : The impact of hunting for biltong purposes on the SA economy. Acta Commercii 2011, 11:1-12.

6. Meat Safety Act 40. Repub South Afr Gov Gaz 2002, 425(21707). http:// www.info.gov.za/view/DownloadFileAction?id=68208.

7. Patterson C, Khosa P: Background Research Paper: A Status Quo Study on the Professional and Recreational Hunting Industry in South Africa. Pretoria: Minister of Environmental Affairs and Tourism; 2005.

8. van der Merwe P, Saayman M: National Profile and Economic Impact of Biltong Hunting in South Africa. Potchefstroom: University of the North West, Institute for Tourism and Leisure Studies; 2008:39.

9. http://www.cites.org/eng/app/appendices.php.

10. http://www.iucnredlist.org.

11. Teletchea F, Maudet C, Hänni C: Food and forensic molecular identification: update and challenges. Trends Biotechnol 2005, 23:359-366.

12. Fajardo V, González I, García T, Rojas M, Martín R: A review of current PCRbased methodologies for the authentication of meats from game animal species. Trends Food Sci Technol 2010, 21:408-421.

13. Alacs EA, Georges A, FitzSimmons NN, Robertson J: DNA detective: a review of molecular approaches to wildlife forensics. Forensic Sci Med Pathol 2010, 6:180-194.

14. Tobe SS, Linacre A: DNA typing in wildlife crime: recent developments in species identification. Forensic Sci Med Pathol 2010, 6:195-206.

15. Kocher TD, Thomas WK, Meyer A, Edwards SV, Pääbo S, Villablanca FX Wilson AC: Dynamics of mitochondrial DNA evolution in animals: amplification and sequencing with conserved primers. Proc Natl Acad Sci US A 1989, 86(16):6196-6200.

16. Irwin D, Kocher T, Wilson A: Evolution of the cytochrome $b$ gene of mammals. J Mol Evol 1991, 32:128-144.

17. Hebert PDN, Cywinska A, Ball SL, deWaard JR: Biological identifications through DNA barcodes. Proc Biol Sci 2003, 270:313-321.

18. Ratnasingham S, Hebert PDN: BOLD: the barcode of life data system. Mol Ecol Notes 2007, 7:355-364

19. Teletchea F, Bernillon J, Duffraisse M, Laudet V, Hänni C: Molecular identification of vertebrate species by oligonucleotide microarray in food and forensic samples. J Appl Ecol 2008, 45:967-975.

20. Harkins GW: Studies on the population genetics of Euphausiids: a comparison of patterns in pelagic taxa displaying different distributions and life-histories. PhD Thesis.: University of the Western Cape; 2006.

21. Linacre AM, Tobe SS: An overview to the investigative approach to species testing in wildlife forensic science. Investigative Genet 2011, 2:2.

22. Tobe SS, Kitchener AC, Linacre AM: Reconstructing mammalian phylogenies: a detailed comparison of the cytochrome $B$ and cytochrome oxidase subunit I mitochondrial genes. PLoS One 2010, 5(11):e14156.

23. Hebert PDN, Stoeckle MY, Zemlak TS, Francis CM: Identification of birds through DNA barcodes. PLOS Biol 2004, 2:1657-1663.

24. Eaton MJ, Meyers GL, Kolokotronis S-O, Leslie MS, Martin AP, Amato G: Barcoding bushmeat: molecular identification of Central African and South American harvested vertebrates. Conserv Genet 2010, 11:1389-1404.

25. Bitanyi S, Bjornstad G, Ernest EM, Nesje M, Kusiluka LJ, Keyyu JD, Mdegela $\mathrm{RH}$, Roed KH: Species identification of Tanzanian antelopes using DNA barcoding. Mol Ecol Resour 2011, 11:442-449.

26. Olayemi A, Oyeyiola A, Antunes A, Bonillo C, Cruaud C, Gaubert P: Contribution of DNA-typing to bushmeat surveys: assessment of a roadside market in south-western Nigeria. Wildlife Research 2011, 38:696-716.

27. Johnston AR, Morikawa MK, Ntie S, Anthony NM: Evaluating DNA barcoding criteria using African duiker antelope (Cephalophinae) as a test case. Conserv Genet 2011, 12:1173-1182.

28. von der Heyden S, Barendse J, Seebregts AJ, Matthee CA: Misleading the masses: detection of mislabelled and substituted frozen fish products in South Africa. ICES J Mar Sci 2010, 67:176-185.

29. Altschul SF, Gish W, Miller W, Myers EW, Lipman DJ: Basic local alignment search tool. J Mol Biol 1990, 215:403-410.

30. Bertolazzi P, Felici G, Weitschek E: Learning to classify species with barcodes. BMC Bioinformatics 2009, 10(Suppl 14):S7.

31. Budowle B, Garofano P, Hellman A, Ketchum M, Kanthaswamy S, Parson W, van Haeringen W, Fain S, Broad T: Recommendations for animal DNA forensic and identity testing. Int J Legal Med 2005, 119:295-302.

32. Linacre A, Gusmão L, Hecht W, Hellmann AP, Mayr WR, Parson W, Prinz M, Schneider PM, Morling N: ISFG: recommendations regarding the use of non-human (animal) DNA in forensic genetic investigations. Forensic Sci Int Genet 2011, 5:501-505.

33. Medrano JF, Aasen E, Sharrow L: DNA extraction from nucleated red blood cells. Biotechniques 1990, 8:43.

34. Parson W, Pegoraro K, Niederstätter H, Föger M, Steinlechner M: Species identification by means of the cytochrome b gene. Int J Legal Med 2000, 114:23-28.

35. Anderson S, de Bruijn MH, Coulson AR, Eperon IC, Sanger F, Young IG: Complete sequence of bovine mitochondrial DNA. Conserved features of the mammalian mitochondrial genome. J Mol Biol 1982, 156:683-717.

36. Folmer $\mathrm{O}$, Black M, Hoeh W, Lutz R, Vrijenhoek R: DNA primers for amplification of mitochondrial cytochrome c oxidase subunit I from diverse metazoan invertebrates. Mol Mar Biol Biotechnol 1994, 3:294-299.

37. http://blast.ncbi.nlm.nih.gov/Blast.cgi.

38. Hall TA: BioEdit: a user-friendly biological sequence alignment editor and analysis program for Windows 95/98/NT. Nucl Acids Symp Ser 1999, 41:95-98.

39. Kimura M: A simple method for estimating evolutionary rate of base substitutions through comparative studies of nucleotide sequences. J Mol Evol 1980, 16:111-120.

40. Hassanin A, Delsuc F, Ropiquet A, Hammer C, van Vuuren Jansen B, Matthee C, Ruiz-Garcia M, Catzeflis F, Areskoug V, Nguyen TT, Couloux A: Pattern and timing of diversification of Cetartiodactyla (Mammalia, Laurasiatheria), as revealed by a comprehensive analysis of mitochondrial genomes. C R Biol 2012, 335:32-50. 
41. Tamura K, Peterson D, Peterson N, Stecher G, Nei M, Kumar S: MEGA5: molecular evolutionary genetics analysis using maximum likelihood, evolutionary distance, and maximum parsimony methods. Mol Biol Evol 2011, 28:2731-2739.

42. van Velzen $\mathrm{R}$, Weitschek E, Felici G, Bakker FT: DNA barcoding of recently diverged species: relative performance of matching methods. PLOS One 2012, 7(1):e30490.

43. Nersting LG, Arctander P: Phylogeography and conservation of impala and greater kudu. Mol Ecol 2001, 10:711-719.

44. Schwab P, Debes PV, Witt T, Hartl GB, Hmwe SS, Zachos FE, Grobler JP: Genetic structure of the common impala (Aepyceros melampus melampus) in South Africa: phylogeography and implications for conservation. J Zool Syst Evol Res 2012, 50:76-84.

45. Van der Walt JM: Detection of genetic substructure and diversity in the endemic South African antelope species Damaliscus pygargus. PhD Thesis. University of Pretoria; 2002

46. Flagstad O, Syvertsen PO, Stenseth NC, Jakobsen KS: Environmental change and rates of evolution: the phylogeographic pattern within the hartebeest complex as related to climatic variation. Proc Biol Sci 2001, 268(1468):667-677.

47. Arctander P, Johansen C, Coutellec-Vreto MA: Phylogeography of three closely related African bovids (tribe Alcelaphini). Mol Biol Evol 1999, 16:1724-1739.

48. Grobler JP, Rushworth I, Brink JS, Bloomer P, Kotze A, Reilly B, Vrahimis S: Management of hybridization in an endemic species: decision making in the face of imperfect information in the case of the black wildebeestConnochaetes gnou. Eur J Wildl Res 2011, 57:997-1006.

49. Lorenzen ED, Masembe C, Arctander P, Siegismund HR: A long-standing Pleistocene refugium in southern Africa and a mosaic of refugia in East Africa: insights from mtDNA and the common eland antelope. J Biogeogr 2010, 37:571-581.

50. Grobler JP, Pretorius DM, Botha K, Kotze A, Hallerman EM, Jansen Van Vuuren $B$ : An exploratory analysis of geographic genetic variation in southern African nyala (Tragelaphus angasii). Mamm Biol 2005, 70:291-299.

51. Moodley Y, Bruford MW, Bleidorn C, Wronski T, Apio A, Plathf M: Analysis of mitochondrial DNA data reveals non-monophyly in the bushbuck (Tragelaphus scriptus) complex. Mamm Biol 2009, 74:418-422.

52. Lorenzen ED, Simonsen BT, Kat PW, Arctander P, Siegismund HR: Hybridization between subspecies of waterbuck (Kobus ellipsiprymnus) in zones of overlap with limited introgression. Mol Ecol 2006, 15:3787-3799.

53. van Vuuren BJ, Robinson TJ: Retrieval of four adaptive lineages in duiker antelope: evidence from mitochondrial DNA sequences and fluorescence in situ hybridization. Mol Phylogenet Evol 2001, 20:409-425.

54. Johnston AR, Anthony NM: A multi-locus species phylogeny of African forest duikers in the subfamily Cephalophinae: evidence for a recent radiation in the Pleistocene. BMC Evol Biol 2012, 12:120.

55. Brown DM, Brenneman RA, Koepfli K-P, Pollinger JP, Milá B, Georgiadis NJ, Louis EE, Grether GF, Jacobs DK, Wayne RK: Extensive population genetic structure in the giraffe. BMC Biol 2007, 5:57.

56. Hassanin A, Ropiquet A, Gourmand A-L, Chardonnet B, Rigoulet J: Mitochondrial DNA variability in Giraffa camelopardalis: consequences for taxonomy, phylogeography and conservation of giraffes in West and central Africa. Comptes Rendus Biologies 2007, 330:265-274

57. Gongora J: Cuddahee RE, do Nascimento FF, Palgrave CJ, Lowden S, Ho SYW, Simond D, Damayanti CS, White DJ, Tay WT, Randi E, Klingel H, Rodrigues-Zarate CJ, Allen K, Moran C, Larson G: Rethinking the evolution of extant sub-Saharan African suids (Suidae, Artiodactyla). Zoologica Scripta 2011, 40:327-335.

58. Muwanika VB, Nyakaana S, Siegismund HR, Arctander P: Phylogeography and population structure of the common warthog (Phacochoerus africanus) inferred from variation in mitochondrial DNA sequences and microsatellite loci. Heredity 2003, 91:361-372.

59. Steiner CC, Mitelberg A, Tursi R, Ryder OA: Molecular phylogeny of extant equids and effects of ancestral polymorphism in resolving species-level phylogenies. Mol Phylogenet Evol 2012, 65(2):573-581.

60. Moodley Y, Harley EH: Population structuring in mountain zebras (Equus zebra): the molecular consequences of divergent demographic histories. Conserv Genet 2005, 6:953-968.

61. Lorenzen ED, Arctander P, Siegismund HR: High variation and very low differentiation in wide ranging plains zebra (Equus quagga): insights from mtDNA and microsatellites. Mol Ecol 2008, 17:2812-2824.
62. Miller JM, Hallager S, Monfort SL, Newby J, Bishop K, Tidmus SA, Black P, Houston B, Matthee CA, Fleischer RC: Phylogeographic analysis of nuclear and mtDNA supports subspecies designations in the ostrich (Struthio camelus). Conserv Genet 2011, 12:423-431.

63. Lorenzen ED, Heller R, Siegismund HR: Comparative phylogeography of African savannah ungulates. Mol Ecol 2012, 21:3656-3670.

64. Spear D, Chown SL: The extent and impacts of ungulate translocations: South Africa in a global context. Biol Conserv 2009, 142:353-363.

65. Smith JM: Probe into Kangaroo meat. The Namibian 2010. http://www. namibian.com.na/index.php?id=28\&tx_ttnews[tt_news]=64004\&no_cache=1.

doi:10.1186/2041-2223-4-6

Cite this article as: D'Amato et al:: Where is the game? Wild meat products authentication in South Africa: a case study. Investigative Genetics 2013 4:6.

\section{Submit your next manuscript to BioMed Central and take full advantage of:}

- Convenient online submission

- Thorough peer review

- No space constraints or color figure charges

- Immediate publication on acceptance

- Inclusion in PubMed, CAS, Scopus and Google Scholar

- Research which is freely available for redistribution 